\title{
A Systematic Review of Substance Use and Substance Use Disorder Research in Kenya
}

FLORENCE JAGUGA ( $\sim$ flokemboi@gmail.com )

Moi Teaching and Referral Hospital https://orcid.org/0000-0002-8381-6309

SARAH KANANA KIBURI

Mbagathi Hospital

EUNICE TEMET

Moi University School of Medicine

JULIUS BARASA

Academic Model Providing Access to Healthcare: AMPATH Kenya

SERAH KARANJA

Gilgil Sub-county Hospital

LIZZ KINYUA

Aga Khan University Hospital

EDITH KWOBAH

Moi Teaching and Referral Hospital

\section{Research}

Keywords: Substance use, substance use disorder, research, systematic review, Kenya, prevalence, intervention, qualitative

Posted Date: July 1st, 2021

DOI: https://doi.org/10.21203/rs.3.rs-631093/v1

License: @) (1) This work is licensed under a Creative Commons Attribution 4.0 International License. Read Full License 


\section{Abstract}

Background: The burden of substance use in Kenya is significant. The objective of this study was to systematically summarize existing literature on substance use in Kenya, identify research gaps, and provide directions for future research.

Methods: This systematic review was conducted in line with the PRISMA guidelines. We conducted a search of 5 bibliographic databases (PubMed, PsychINFO, Web of Science, Cumulative Index of Nursing and Allied Professionals (CINAHL) and Cochrane Library) until 20 August 2020 . In addition we searched all the volumes of the official journal of the National Authority for the Campaign Against Alcohol \& Drug Abuse (the African Journal of Alcohol and Drug Abuse). The results of eligible studies have been summarized descriptively and organized by the three broad categories: (1) Studies evaluating the epidemiology of substance use, (2) studies evaluating interventions and programs, and (3) qualitative studies exploring various themes on substance use. The quality of the included studies was assessed with the Quality Assessment Tool for Studies with Diverse Designs.

Results: Of the 185 studies that were eligible for inclusion, 144 investigated the epidemiology of substance use, 23 qualitatively explored various substance use related themes, and 18 evaluated substance use interventions and programs. Key evidence gaps emerged. Firstly, vulnerable populations such as police officers, pregnant women, health care workers and persons with physical disability had been under-represented within the epidemiological and qualitative work. Secondly, no intervention study had been conducted among children and adolescents. Thirdly, most interventions had focused on alcohol to the exclusion of other prevalent substances such as tobacco and cannabis. Finally, little had been done to evaluate digital and population-level interventions.

Conclusions: The results of this systematic review provide important directions for future substance use research in Kenya.

Systematic review registration: PROSPERO: CRD42020203717

\section{Background:}

Globally, substance use is associated with significant morbidity and mortality. In the 2017 Global Burden of Disease (GBD) study, substance use disorders (SUDs) were the second leading cause of disability among the mental disorders with 31,052,000 (25\%) Years Lived with Disability (YLD) attributed to them (1). In 2016, harmful alcohol use resulted in 3 million deaths (5.3\% of all deaths) worldwide and 132.6 (5.1\%) million disability-adjusted life years (DALYs) (2). Tobacco use, the leading cause of preventable death, kills more than 8 million people annually (3). Even though the prevalence of opioid use is small compared to that of tobacco and alcohol use, opioid use disorder contributes to $76 \%$ of all deaths from SUDs (4). Other psychoactive substances such as cannabis and amphetamines are similarly associated with significant health consequences (4). In addition to their impact on health, substance use is associated with significant socio-economic costs arising from their impact on health and criminal justice systems (5).

Low- and middle-income countries (LMICs) bear the burden of substance use. Over $80 \%$ of the 1.3 billion tobacco users worldwide live in LMICs (3). In 2016, the alcohol-attributable disease burden was highest in LMICs compared to upper-middle-income and high-income countries (HICs) (2). In Kenya, a nationwide survey conducted in 2017 reported that over $10 \%$ of Kenyans between the ages of 15 to 65 years had a SUD (6). In another survey, 20\% of primary school children had ever used at least one substance in their lifetime (7). Moreover, Kenya has the third highest total DALYs (54,000) from alcohol use disorders (AUD) in Africa (4). Unfortunately, empirical work on substance use in LMICs is limited $(8,9)$. In a global mapping of SUD research, majority of the work had been conducted in upper-middle income and HICs (HICs) (9). In a study whose aim was to document the existing work on mental health in Botswana, only 7 studies had focused on substance use (8). Information upon which policy and interventions could be developed is therefore lacking in lowand-middle income settings.

Since the early 1980s, scholars in Kenya began engaging in research to document the burden and patterns of substance use (10). In 2001 the National Authority for the Campaign Against Alcohol and Drug Abuse (NACADA) was set up in response to the rising cases of harmful substance use in the country particularly among the youth. The mandate of the Authority was to educate the public on the harms associated with substance use (11). In addition to prevention work, NACADA contributes to research by conducting 5 year general population prevalence surveys and recently launched its journal, the African Journal of Alcohol and Drug Abuse (AJADA) (12). The amount of empirical work done on substance use in Kenya has expanded since these early years but has not been systematically summarized, and therefore the evidence gaps remain unclear.

In order to guide future research efforts and adequately address the substance use scourge in Kenya, there is need to document the scope and breadth of available scientific literature. The aim of this systematic review is therefore: (1) To describe the characteristics of research studies conducted on substance use and SUD in Kenya; (2) To assess the methodological quality of the studies; (3) To identify areas where there is limited research evidence and (4) To make recommendations for future research. This paper is in line the Vision 2030 (13), Kenya's national development policy framework, which directs that the government implements substance use treatment and prevention projects and programs, and target 3.5 of the Sustainable Development Goals (SDGs) which requires that countries strengthen the treatment and prevention for SUDs (14).

\section{Methods:}

\section{Protocol and registration}

In conducting this systematic review we adhered to the recommendations from the Preferred Reporting Items for Systematic Reviews and Meta-Analyses (PRISMA) statement (15). A 27-item PRISMA checklist is available as an additional file to this protocol (Additional file 1). Our protocol was registered in the International Prospective Register of Systematic Reviews (PROSPERO): CRD42020203717.

Page $2 / 19$ 


\section{Search strategy}

A search was carried out in five electronic databases: PubMed, PsychINFO, Web of Science, Cumulative Index of Nursing and Allied Professionals (CINAHL) and Cochrane Library. The full search strategy can be found in Additional file 2 and takes the following form: (terms for substance use) and (terms for substance use outcomes of interest) and (terms for region). The searches spanned the period from inception to date. No filter was applied. A manual search was done in Volumes 1, 2 and 3 (all published volumes by the time of the search) of the recently launched AJADA journal from the NACADA website and additional articles identified $(12,16,17)$.

\section{Study selection}

Following the initial search, all articles were loaded onto Rayyan, a soft-ware for screening and selecting studies during the conduct of systematic reviews (18), and checked for duplicates. After duplicate removal, the abstract and titles of retrieved articles were independently screened by two authors based on a set of pre-determined eligibility criteria. A second screening of full text articles was also done independently by two authors and resulted in an $88.7 \%$ agreement. Disagreements during each stage of the screening were resolved through discussion and consensus.

\section{Inclusion criteria}

Since we sought to map existing literature on the subject, our inclusion criteria were broad. We included all studies on substance use if (i) the sample or part of the sample was from Kenya, (ii) they were original research articles, (iii) they had a substance use exposure, (iv) they had a substance use/SUD related outcome such as prevalence, pattern of use, prevention and treatment, and (iv) they were published in English or had an English translation available. We included studies conducted among all age groups and studies that used all designs both quantitative and qualitative.

\section{Exclusion criteria}

Studies were excluded if: (i) they were cross-national and did not report country specific results (ii) they did not report substance use as an exposure, and did not have substance use related outcomes or as part of the outcomes, (iii) they were review articles, dissertations, conference presentations/abstracts, commentaries or editorials, (iv) and the full text articles were not available.

\section{Data extraction and synthesis}

We prepared 3 data extraction forms based on three categories of studies i.e.:

1. Studies reporting on the epidemiology of substance use/SUD

2. Studies evaluating substance use/SUD interventions and programs

3. Studies qualitatively exploring various themes on substance use/SUD (but not assessing interventions)

The forms were piloted by F.J. and S.K. and adjustments made to the content. Data extraction was then done using the final form by all authors and double checked by F.J. for completeness and accuracy. Discrepancies were resolved by discussion with S.K. and E.T. until consensus was achieved. The following data was extracted for each study category:

1. Studies reporting on the epidemiology of substance use/SUD: study design, study population characteristics, study setting, sample size, age and gender distribution, substance(s) assessed, standardized tool/criteria used, main findings (prevalence, risk factors, other key findings).

2. Studies evaluating substance use/SUD interventions and programs: study design, study objective, sample size, name of the intervention/program, person delivering intervention, outcomes and measures, and main findings

3. Studies qualitatively exploring various aspects of substance use/SUD other than programs and interventions: study objective, methods of data collection, study setting, study population, age and gender distribution, and main findings

The results have been summarized descriptively and organized by the three categories above.

\section{Quality assessment of the studies}

Quality assessment was conducted by S.K. using the Quality Assessment Tool for Studies with Diverse Designs (QATSDD) (19). F.J. \& J.B. double checked the scores for completeness and accuracy. Any disagreements were discussed and resolved by consensus. We had initially planned to use the National Institute of Health $(\mathrm{NIH})$ set of quality assessment tools but due to the diverse nature of study designs, the authors agreed to use the QATSDD tool. The QATSDD is a 16-item tool for both qualitative and quantitative studies. Each item is scored on a 4-point scale (0-3), with a total of 14 criteria for each study design and 16 for studies with mixed methods. Scoring relies on guidance notes provided as well as judgment and expertise from the reviewers. The criteria used are : (i) theoretical framework; (ii) statement of aims/objectives; (iii) description of research setting; (iv) sample size consideration; (v) representative sample of target group (vi) data collection procedure description; (vii) rationale for choice of data collection tool(s); (viii) detailed recruitment data; (ix) statistical assessment of reliability and validity of measurement tools (quantitative only); (x) fit between research question and method of data collection (quantitative only); (xi) fit between research question and format and content data collection (qualitative only); (xii) fit between research question and method of analysis ; (xiii) justification of analytical method; (xiv) assessment of reliability of analytical process (qualitative only); (xv) user involvement in design and (xvi) discussion on strengths and limitations (19). Scores are awarded for each criterion as follows: $0=$ no mention at all; $1=$ very brief description; 2 = moderate description; and 3 = complete description. The scores of each criterion are then summed up with a maximum score of 48 for mixed methods studies and 42 for studies using either qualitative only or quantitative only designs. For ease of interpretation, the scores were converted to percentages and classified as low (<50\%), medium (50-80\%) or high $(>80 \%)$ quality of evidence (20). 


\section{Results:}

\section{Search results}

The search from the five electronic databases and yielded 1535 results: 950 from PubMed, 173 from PsychINFO, 210 from web of science, 123 from CINAHL and 79 from Cochrane library. A further 13 studies were identified through a manual search of the AJADA journals (Volumes 1, 2 and 3). Studies were assessed for duplicates and 1154 articles remained after removal of duplicates. These underwent an initial screening based on abstracts and titles, and 946 articles were excluded. A second screen of full text articles was done for the 208 studies that were potentially eligible for the review. Twenty three studies were excluded as follows: 21 did not meet the eligibility criteria and 2 had duplicated results. A total of 185 studies were found to meet the inclusion criteria and were included in the review (Fig 1).

\section{General description of studies}

Of the 185 studies included in this review, 144 (77.8\%) investigated the epidemiology of substance use/SUD (Additional file 3), 18 (9.7\%) evaluated substance use/SUD interventions and programs (Additional file 4), and 23 (12.4\%) were qualitative studies exploring perceptions on various substance use/SUD topics (Additional file 5). The studies were published between 1982 and 2020. The number of studies published has gradually increased in number over the years, particularly in the past decade. The graph below shows the trends in publications on substance use in Kenya.

\section{Quality assessment:}

The QATSDD scores ranged from $28.6 \%$ (21) to $92.9 \%$ (22). Only 14 studies $(10,21,23-34$ ) (all quantitative) had scores of less than $50 \%$. Of these, the main items driving low quality were: no mention of user involvement in study design $(n=14)(10,21,23-34)$, no explicit mention of a theoretical framework ( $n=10)$ $(10,21,23,25-30,32)$ and a lack of a statistical assessment of reliability and validity of measurement tools $(n=10)(10,21,23,25-27,30,32-34)($ Additional file $6)$.

\section{Studies examining the epidemiology of substance use/SUD}

Description of epidemiological studies: 144 studies examined the prevalence and or risk factors for various substances. The studies were published between 1982 and 2020. The 4 main study designs were cross-sectional $(n=126)$, cohort $(n=5)$, case-control $(n=10)$, and mixed methods ( $n=2)$. One study used a combination of the 'multiplier method', 'Wisdom of the Crowds' (WOTC) method and a published literature review to document the size of key populations (35). The sample size for this category of studies ranged from 42 (36) to 72292 (37).

The studies were conducted in diverse settings including the community $(n=72)$, hospitals $(n=41)$, institutions of learning ( $n=24)$, streets ( $n=5)$, prisons and courts $(n=3)$, in charitable institutions $(n=1)$, and in needle-syringe program (NSP) sites $(n=1)$. Of the studies conducted within the community, 12 were conducted in informal settlements. The study populations were similarly diverse as follows: general population adults \& adolescents ( $\mathrm{n}=39$ ), persons with $\operatorname{NCDs}(n=11)$, primary and secondary school students $(n=15)$, people with injecting drug use (PWID) $(n=11)$, general patients $(n=5)$, Men who have Sex with Men (MSM) $(n=8)$, university and college students $(n=9)$, commercial sex workers $(n=7)$, psychiatric patients $(n=6)$, orphans and street connected children and youth $(n=6)$, people living with HIV (PLHIV) $(n=6)$, healthcare workers $(n=3)$, law offenders $(n=3)$, military $(n=1)$, and teachers $(n=1)$. Only one study was conducted among pregnant women (38).

Sixty nine studies (47.6\%) used a standardized diagnostic tool to assess for substance use. The AUDIT ( $n=21)$ and the ASSIST ( $n=10)$ were the most frequently used tools. Most papers assessed for alcohol $(n=109)$ and tobacco $(n=80)$. Other substances assessed included amphetamines $(n=41)$, opioids (21), sedatives $(n=19)$, cocaine $(n=19)$, inhalants $(n=16)$, cannabis $(n=14)$, hallucinogens $(n=7)$, prescription pills $(n=2)$, emerging drugs $(n=1)$ and ecstasy $(n=1)$.

Key findings on prevalence rates: One studywith the largest sample size ( $n=72292)$ drawn from the community, reported the lifetime prevalence of tobacco smoking among adults as $11.2 \%$ and that of alcohol use as $20.7 \%$ (37). Using the Alcohol Use Disorder Identification Test (AUDIT), the 12 month prevalence of hazardous alcohol use ranged from $2.9 \%$ among adults drawn from the community (39), and 64.6\% among female sex workers (FSW) (40). Based on the same tool, the lowest and highest rates of harmful alcohol use were both reported among FSWs i.e. 9.3\% (41) and 64.0\% (42) respectively, while the prevalence of alcohol dependence ranged from $8 \%$ among FSWs living with HIV (43) to $33 \%$ among MSM who sold sex (44).

Based on the Alcohol, Smoking \& Substance Use Involvement Screening Test (ASSIST) questionnaire, the lifetime prevalence of tobacco use ranged from $23.5 \%$ among health care workers (HCWs) (45) to $95.7 \%$ among university students (46), that of khat use ranged from $11.5 \%$ among university students (47) to $55.2 \%$ among psychiatric inpatients (48), and that of cannabis use from $21.3 \%$ among persons with AUD (49) to $64.2 \%$ among psychiatric in-patients (48). The lifetime prevalence of opioid use ranged from 1.1\% among PLHIV (50) to $8.2 \%$ among psychiatric in-patients as assessed using the ASSIST (48).

Key findings on associated/risk factors: Among children, youth and adolescents, substance use was associated with being male (32), engaging in sex (51), older age (52,53), being in a private school, living in an urban area (53), having a family member who uses substances (52), depression (38,54), suicidal behavior (55) and Human Immunodeficiency Virus (HIV) infection (56). Early substance use among this population was linked to ever engaging in sex, higher education, parental or guardian substance use, and suicidal ideation (57). Factors associated with multiple substance use were living in an urban area and being female (58).

Among adults, alcohol use was associated with several socio-demographic factors including being male (45,59-66), being unemployed (61), being selfemployed (62), having a lower socio-economic status (SES) (37), being single or separated, living in large households (62), having a family member 
struggling with alcohol use and alcohol being brewed in the home (67). Alcohol use was linked to various health factors including glucose intolerance (68); poor cardiovascular risk factor control (69), having a diabetes mellitus diagnosis (70), hypertension (65,71), default from tuberculosis (TB) treatment (72), depression (49), psychological Intimate Partner Violence (IPV) (73), physical and sexual violence (74), tobacco use (66,73), and increased risk laryngeal (75) and esophageal cancer $(76,77)$. Finally alcohol use was associated with involvement in Road Traffic Accidents (RTAs) (78,79), having injuries (78,80,81), and with having concurrent sexual relationships (66).

Tobacco use among adults was associated with being male $(45,59,65)$. Several health factors were linked to tobacco use including hypertension $(65)$, development of oral leukoplakia (34), pneumonia (82), increased odds esophageal cancer (77), ischemic stroke (83) and diabetes mellitus (70). In addition, tobacco use was associated with having had an injury in the last 12 months (81), emotional abuse (48) and psychological IPV (73). Longer duration of smoking was associated with a diagnosis of diabetes mellitus (84), lower SES (37), and hypertension $(85,86)$.

Two case-control studies documented increased odds of reporting psychotic symptoms (87,88), and PTSD (Post-Traumatic Stress Disorder) symptoms (88) among khat users compared to non-users, while IDU was associated with depression, risky sexual behavior (89), Hepatitis-C Virus (HCV) infection (90), and HIV-HCV co-infection (91).

Other topics explored:In addition to prevalence and associated factors, these studies explored other topics including agreement between self-reported alcohol use and the biomarker phosphatidyl ethanol (92), primary health care workers self-efficacy for SUD management (93), reasons for substance use $(27,30,94,95)$, and tobacco quit intentions(96). Papas et al. (92) reported a lack of agreement between self-reported alcohol use and the biomarker phosphatidyl ethanol among PLHIV with AUD. Among primary health care workers, self-efficacy for SUD management was lower in those practicing in public facilities and perceiving a need for AUD training. In that study, higher self-efficacy correlated with a higher proportion of patients with AUD in one's setting, access to mental health worker support, HCW's cannabis use at a moderate risk level, and belief that AUD is manageable in outpatient settings. Common reasons for substance use included leisure, stress and peer pressure among psychiatric in-patients (30), curiosity, fun, and peer influence among college students (94); peer influence, idleness, easy access, and curiosity among adults in the community (27); and peer pressure, to get drunk, to feel better and to feel warm among street children (95). Atwoli et al. 2011 (97) reported that most students were introduced to substances by friends while Astrom et al. 2004 (98) reported that HCWs, parents and school teachers were not discussing tobacco harms with youth. Kaai et al. 2019 (96) conducted a study regarding quit intentions for tobacco use and reported that $28 \%$ had tried to quit in past 12 months; $60.9 \%$ had never tried to quit, only $13.8 \%$ had ever heard of smoking cessation medication. Intention to quit smoking was associated with being younger, having tried to quit previously, perceiving that quitting smoking was beneficial to health, worrying about future health consequences of smoking, and being low in nicotine dependence. A complete description of the prevalence studies has been provided in additional file 3 .

\section{Studies evaluating substance use/ SUD programs and interventions}

A total of eighteen studies evaluated specific interventions or programs for the treatment and prevention of substance use (see Additional file 4). These were carried out between 2009 and 2020. The studies used various approaches including randomized control trials (RCT) (99-105) mixed methods (106-108), non-concurrent multiple baseline design (109), quasi experimental (110), cross-sectional $(111,112)$, and qualitative (113-115). One study employed a combination of qualitative methods and mathematical modeling (116).

11 studies investigated feasibility, acceptability or efficacy of individual-level treatment or prevention interventions using various outcomes. The interventions evaluated included cognitive behavioral therapy (CBT) $(101,106)$, motivational interviewing (MI) (99), a combination of behavioral activation, $\mathrm{MI}$ and gender norm transformative strategies (109), World Health Organization (WHO) brief intervention $(100,102,103,107,110)$, psychoeducation sessions (105), and contingency management (104). Only one study evaluated family outcomes (109). All interventions were tested among adult populations. These included persons attending a Voluntary Counseling \& Testing (VCT) center (107), PLHV (101,106), college students (105), FSWs (100,102), and adult males and females $(103,109,110)$ drawn from the community.

The interventions were delivered using various approaches including trained lay providers $(101,106,109,110)$, digital health means (99), and trained primary care workers such as nurses $(100,102)$, and VCT service providers (Mackenzie 2009). The number of sessions ranged from one (103,107) to six (100$102,106)$. Most of the individual level interventions targeted harmful alcohol use $(n=9)(99-102,104,106,107,109,110)$. One study targeted khat use among men (103), while another the use of multiple substances (105). All interventions had a positive impact on substance use except the study that used the contingency management approach (104). The interventions were delivered in various settings as follows: community settings ( $\mathrm{n}=6)(99,102-104,109,110)$ of which one was delivered in a HIV prevention drop in center (102), HIV treatment or testing out-patient clinics $(n=3)(101,106,107)$, alcohol and drug abuse rehabilitation facility $(n=1)(100)$, and within a college $(n=1)(105)$. One study described the process of culturally adapting a CBT intervention for alcohol use, for use among a population of PLHIV (106).

Five studies evaluated various aspects of substance use treatment programs. The studies evaluated perceptions on benefits of methadone programs $(113,116)$ and NSPs $(115)$, healthcare workers knowledge and practices on tobacco cessation (112), and utilization of community based outpatient SUD treatment services (111). The methadone and NSP programs were perceived as beneficial and impactful by stakeholders and service users (113,115) and knowledge and practice on tobacco cessation as inadequate (112). Deveau et al., 2010 (111) reported a $42 \%$ abstinence rate 0-36 months post-treatment termination.

Two studies evaluated population-level interventions. One evaluated the appropriateness and effectiveness of HIC anti-tobacco adverts in the African context and found the adverts to be effective and appropriate (108). Another study that examined community member's perspectives on the impact of the 
government's public education messages on alcohol abuse reported the messages as ineffective and unpersuasive (114). A complete description of included intervention studies is in additional file 4.

\section{Studies qualitatively exploring various substance use/SUD topics (other than interventions)}

There were 23 qualitative studies included in our review. The studies were conducted between 2004 and 2020. Data was collected using several approaches including in-depth interviews (IDIs) only $(n=6)(117-121)$, focus group discussions (FGDs) only $(n=2)(122,123)$, a combination of FGDs and IDIs ( $n=10)$ $(114,124-132)$, a combination of observation and individual IDIs $(120,133)$, a combination of observation, IDIs and FGDs (134), a combination of literature review, observation, IDIs and FGDs (132). One study utilized the participatory research and action approach (135).

The study populations for the qualitative studies included persons using heroin $(129,133)$, males and females with IDU $(116,119,124,125,127,136)$, community based organizations (114,123), youth $(120,131,134)$, FSWs $(118,121)$, refugees and Internally Displaced Persons (IDPs) (132), and PLHIV $(122,135)$.

Various themes were explored in these qualitative studies including risk and protective factors for substance use $(120,127,131,134)$, health and or socioeconomic effects of substance use $(119,122,123,130,132)$, perceptions on heroin use (133), transitions from heroin smoking to injection (117), and stages of change in participants enrolled in an intervention (121). Substance use was perceived as having a negative socio-economic and health impact (122,132). Specifically, substance use was perceived to have a negative impact on contraceptive use (128), on utilization of antenatal and maternal \& child health services (137), as well as on sexual and reproductive health (130). In addition, substance use emerged as a driver of risky sexual behavior and HIV among both adults $(118,138)$ and adolescents $(120,134)$. Several factors were perceived to contribute to substance use including gender inequality, influence of intimate partners and the need to cope with stress among women $(119,124,125)$, and stigma and perceived medicinal value among PLHIV (135). Finally, access to care for substance use was reported as limited $(119,132,135)$.

\section{Discussion:}

This is to our knowledge, the first study to summarize empirical work done on substance use and SUDs in Kenya. More than a half (77.8\%) of the reviewed studies investigated the area of prevalence and risk factors. Less common were qualitative studies exploring various themes (12.4\%) and studies evaluating interventions and programs (9.7\%). The first study was conducted in 1982 and since then the number of publications has gradually risen. Most of the research papers (92.4\%) were of moderate to high quality. The review finds that comparatively a lot of research work has been done on substance use in Kenya in relation to other Sub-Saharan African (SSA) countries, with 185 papers published by the time of the search. Two recent scoping reviews, reported that only 53 and 7 papers focusing on substance use had been published in South Africa (between 1971 and 2017) (9) and in Botswana (between 1983 and 2020) respectively (8).

\section{Epidemiology of substance use/SUD}

Studies assessing prevalence, patterns and risk factors dominated the literature. The studies were conducted across a broad range of study settings and populations. In addition, a wide range of important health and socio-demographic factors were examined for their association with substance use. Most studies had robust sample sizes and were conducted using diverse designs including cross-sectional, case-control and cohort. The studies showed a significant burden of substance use among both adults and children and adolescents. In addition substance use increased the odds of negative mental and physical health outcomes consistent with findings documented in global reports $(2,3)$. These findings highlight the importance of making the treatment and prevention of substance use and SUDs of high priority in Kenya.

Key evidence gaps were identified within this category:

1. The prevalence and risk factors for substance use among certain vulnerable populations for whom substance use can have severe negative consequences, had not been investigated. For example, no study had included police officers or persons with physical disability, only one study had its participants as pregnant women (38), and only 2 studies had been conducted among HCWs $(93,139)$.

2. The prevalence of emerging substances was investigated by only one study (140). These substances are increasingly becoming a public health threat globally (141) yet their use remains poorly documented in Kenya

\section{Interventions and programs}

Given the significant documented burden of substance use and SUDs in Kenya, it was surprising that few studies had focused on developing and testing treatment and prevention interventions for substance use. A possible reason for this is limited expertise in the area of intervention development and testing. For example, research capacity in implementation science has been shown to be limited in resource-poor settings such as ours (142).

Of note is that most of the tested interventions had been delivered by lay providers $(101,106,109)$ and primary care workers $(100,102,107)$ indicating a recognition of task-shifting as a strategy for filling the mental health human resource gap in Kenya.

Overall, study findings indicated feasibility and benefit for the programs and interventions evaluated except for one study which showed no effect for a contingency management type intervention (104). Several research gaps were identified within this category. 
1. Out of the 11 individual-level interventions tested, all targeted alcohol use except one which focused on khat (103) and another that targeted several substances (105). No individual-level interventions targeted tobacco and cannabis use despite the two being the second and third most commonly used substances in Kenya (6).

2. Few studies had evaluated the impact of population-level interventions $(108,114)$. Several cost-effective population-level interventions have been recommended by WHO e.g. mass media education and national toll free quit line services for tobacco use, and brief interventions integrated into all levels of primary care for harmful alcohol use (143). Such strategies need to be tested for scaling up in Kenya.

3. None of the interventions had been tested among important vulnerable populations for whom local research already shows a significant burden e.g. children and adolescents, the Lesbian Gay Bisexual Transgender \& Queer (LGBTQ) community, HCWs, prisoners, and refugees and IDPs. In addition, no interventions had been tested for police officers and pregnant women, and no studies had evaluated interventions to curb workplace substance use.

4. Only one study evaluated digital strategies for delivering substance use interventions (99) yet the feasibility of such strategies has been demonstrated for other mental disorders in Kenya (144). Moreover, the time is ripe for adopting such an approach to substance use treatment given the fact that the country currently has a mobile subscriptions penetration of greater than $90 \%$ (145).

5. No studies had evaluated the impact of other interventions such as mindfulness and physical exercise. Meta-analytic evidence suggests that such strategies hold promise for reducing the frequency and severity of substance use and craving $(146,147)$.

\section{Qualitative studies}

The qualitative studies provided in-depth understanding of the factors contributing to, and the socio-economic and health impact of substance use among both adults and adolescents. Most of the work however focused on PWID use and FSWs. Future qualitative work should focus on examining the drivers and impact of substance use in several other populations for example persons with other mental disorders, persons with physical disabilities, police officers, and persons using other substances such as tobacco and cannabis.

\section{Limitations}

The aim of this systematic review was to provide an overview of the existing literature on substance use and SUD research in Kenya, we therefore did not undertake a meta-analysis and detailed synthesis of the findings of studies included in this review. In addition, variability in measurements of substance use outcomes precluded ability to summarize the study findings. For quality assessment, detailed assessments using design specific tools were not possible given the diverse methodological approaches utilized in the studies. We therefore used a single tool for the quality assessment of all studies. The results of the quality assessment are therefore to be interpreted with caution. Nonetheless this review describes for the first time the breadth of existing literature on substance use and SUDs in Kenya, identifies research gaps and provides important directions for future research.

\section{Conclusion:}

The purpose of this systematic review was to map the research that has been undertaken on substance use and SUDs in Kenya. Epidemiological studies dominated the literature and indicated a significant burden of substance use among both adults and adolescents. Our findings indicate that there is a dearth of literature regarding interventions for substance use and we are calling for further research in this area. Specifically, interventions ought to be tested not just for alcohol but for other substances as well, and among important at risk populations. In addition, future research ought to explore the feasibility of delivering substance use interventions using digital means, and the benefit of other interventions such as mindfulness and physical exercise. Future qualitative work should aim at providing in-depth perspectives on substance use among a populations excluded from existing literature e.g. police officers, persons using other substances such as tobacco and cannabis and persons with physical disability.

\section{List Of Abbreviations:}

ASI Addiction Severity Index

ASSIST Alcohol Smoking and Substance Involvement Screening Test

AUD Alcohol Use Disorder

AUDIT Alcohol Use Identification Test

AUDIT-C Alcohol Use Identification Test - Concise

BAl Beck Anxiety Inventory

BDI Beck Depression Inventory

BHS Behavioral Health Screen

BMI Body Mass index

BSIS Beck Suicidal Intent Scale

CAD Coronary Artery Disease

Page $7 / 19$ 
CAGE Cut, Annoyed, Guilty, Eye-opener

CIDI Composite International Diagnostic Interview

CINAHL Cumulative Index of Nursing and Allied Professionals

CRAFFT Car, Relax, Alone, Forget, Friends, Trouble

DAST Drug Abuse Screening Test

DSM-III Diagnostic \& Statistical Manual Third Edition

DSM-III R Diagnostic \& Statistical Manual Third Edition Revised

DSM-IV Diagnostic \& Statistical Manual Fourth Edition

DSM-V Diagnostic \& Statistical Manual Fifth Edition

DUSI-R Drug Use Screening Inventory - Revised

FGD Focus Group Discussion

FSW Female Sex Workers

GSHS Global School-based Health Survey

HCV Hepatitis C Virus

HCW Healthcare worker

HIC High Income Country

HIV Human Immunodeficiency Virus

ICD International Classification of Disease

IDI In-depth Interviews

IDP Internally Displaced Persons

IPV Intimate Partner Violence

KIls Key Informant Interviews

K-SADS Kiddie-Schedule for Affective Disorders

LGBTQ Lesbian, Gay, Bisexual, Transgender, Queer

LMIC Low and Middle Income Country

MAST Michigan Alcohol Screening Test

MI Motivational Interviewing

MINI Mini International Neuropsychiatric Interview

MMT Methadone Maintenance Therapy

MPBI Multiple Problem Behavior Inventory

MSM Men who have Sex with Men

MSME Men who have Sex with Men Exclusively

MSMW Men who have Sex with Men \& Women

NIH National Institute of Health

NSP Needle Syringe Program

OST Opioid Substitution Therapy 
PLHV People Living with HIV

PrEP Pre-exposure Prophylaxis

PTSD Post-Traumatic Stress Disorder

PWID People With Injecting Drug Use

QATSDD Quality Assessment Tool for Studies with Diverse Designs

RCT Randomized controlled trial

RTAs Road Traffic Accidents

SCID Structured Clinical interview for DSM

SES Socio-economic Status

SSA Sub-Saharan Africa

TB Tuberculosis

UNODC United Nations Office on Drugs and Crime

VCT Voluntary Counseling \& Testing

WOTC Wisdom of the Crowds

\section{Declarations:}

\section{Ethics approval and consent to participate}

Not applicable

\section{Consent for publication}

Not applicable

\section{Availability of data and materials}

All data generated or analyzed during this study are included in this published article [and its supplementary information files].

\section{Competing interests}

The authors declare that they have no competing interests.

\section{Funding}

There are no sources of funding to declare

\section{Authors' contributions}

F.J. and S.K. developed the protocol for the systematic review. S.K. searched the databases. S.K. and F.J. conducted the screening and selection of studies. All authors contributed to data extraction. Quality assessment was done by S.K., F.J. and J.B. All authors contributed to report writing. All authors read and approved the final manuscript.

\section{Acknowledgements}

Not applicable

\section{References:}

1. GBD 2017 Disease and Injury Incidence and Prevalence Collaborators. Global, regional, and national incidence, prevalence, and years lived with disability for 354 diseases and injuries for 195 countries and territories, 1990-2017: a systematic analysis for the Global Burden of Disease Study 2017 [published correction appears in Lancet. 2019 Jun 22;393(10190):e44]. Lancet. 2018;392(10159):1789-1858. doi:10.1016/S0140-6736(18)32279-7

2. Hammer JH, Parent MC, Spiker DA, World Health Organization. Global status report on alcohol and health 2018. https://apps.who.int/iris/bitstream/handle/10665/274603/9789241565639-eng.pdf?ua=1. Accessed 12 June 2021

3. World Health Organisation. Tobacco [Internet]. 2020. https://www.who.int/news-room/fact-sheets/detail/tobacco. Accessed 12 June 2021 
4. World Health Organization. Alcohol and drug use disorders: Global health estimates. 2017.

http://www.who.int/substance_abuse/activities/fadab/msb_adab_2017_GHE_23June2017.pdf. Accessed 12 June 2021

5. International Narcotics Control Board. Chapter 1: Economic consequences of drug abuse. 2013.

https://www.incb.org/documents/Publications/AnnualReports/AR2013/English/AR_2013_E_Chapter_I.pdf. Accessed 12 June 2021

6. National Authority for the Campaign Against alcohol and Drug Abuse. Rapid Situation Assessment of Drugs abd Substance Abuse in Kenya. 2017. https://nacada.go.ke/sites/default/files/2019-10/National\%20ADA\%20Survey\%20Report\%202017_2_2.pdf. Accessed 12 June 2021

7. National Authority for the Campaign Against alcohol and Drug Abuse, Kenya Institute for Public Policy Research and Analysis. Status of Drugs and Substance Abuse among Primary School Pupils in Kenya. 2019. https://nacada.go.ke/sites/default/files/2019-

10/Report\%20on\%20the\%20Status\%20of\%20Drugs\%20and\%20Substance\%20Abuse\%20among\%20Primary\%20School\%20Pupils\%20in\%20Kenya.pdf. Accessed 12 June 2021

8. Opondo PR, Olashore AA, Molebatsi K, Othieno CJ, Ayugi JO. Mental health research in Botswana: a semi-systematic scoping review. J Int Med Res. 2020;48(10):300060520966458. doi:10.1177/0300060520966458

9. Tran BX, Moir M, Latkin CA, Hall BJ, Nguyen CT, Ha GH, et al. Global research mapping of substance use disorder and treatment 1971-2017: Implications for priority setting. Subst Abus Treat Prev Policy. 2019; 14(1):21.

10. Dhadphale M, Mengech HN, Syme D, Acuda SW. Drug abuse among secondary school students in Kenya: a preliminary survey. East Afr Med J. 1982;59(2):152-6. PMID: 6982160.

11. The National Authority for the Campaign aganist Alcohol and Drug Abuse [Internet]. http://www.nacada.go.ke. Accessed 12 June 2021

12. The National Authority for the Campaign Aganist Alcohol and Drug Abuse. African Journal of Alcohol \& Drug Abuse (Volume 2). https://nacada.go.ke/sites/default/files/AJADA/AJADA\%202\%20ammended/AJADA\%20Volume\%20II\%20(Full\%20Booklet).pdf. Accessed 12 june 2021

13. Republic of Kenya. The National Treasury and Planning. Third Medium Term Plan 2018-2022. Kenya Vision 2030. https://planning.go.ke/wpcontent/uploads/2018/12/THIRD-MEDIUM-TERM-PLAN-2018-2022.pdf. Accessed 20 June 2020

14. UNDP. The 2030 Agenda for Sustainable Development, A/RES/70/1. Undp. 2015.

15. Liberati A, Altman D G, Tetzlaff J, Mulrow C, GÃ,tzsche P C, loannidis J P A et al. The PRISMA statement for reporting systematic reviews and metaanalyses of studies that evaluate healthcare interventions: explanation and elaboration. BMJ. 2009; 339 :b2700 doi:10.1136/bmj.b2700

16. The National Authority for the Campaign Aganist Alcohol and Drug Abuse. African Journal of Alcohol \& Drug Abuse (Volume 1). https://nacada.go.ke/sites/default/files/AJADA/AJADA\%201\%20ammended/AJADA\%20Volume\%20l\%20(Full\%20Booklet).pdf. Accessed 12 june 2021

17. The National Authority for the Campaign Aganist Alcohol and Drug Abuse. African Journal of Alcohol \& Drug Abuse (Volume 3). https://nacada.go.ke/sites/default/files/AJADA/AJADA\%203/NACADA\%20AJADA\%20Vol\%203-\%20Full\%20Booket.pdf. Accessed 12 june 2021

18. Ouzzani M, Hammady H, Fedorowicz Z, Elmagarmid A. Rayyan - a web and mobile app for systematic reviews. Systematic Reviews (2016) 5:210, DOI: 10.1186/s13643-016-0384-4.

19. Sirriyeh R, Lawton R, Gardner P, Armitage G. Reviewing studies with diverse designs: The development and evaluation of a new tool. J Eval Clin Pract. 2012;18(4):746-52.

20. Alele F, Malau-Aduli B, Malau-Aduli A, Crowe M. Systematic review of gender differences in the epidemiology and risk factors of exertional heat illness and heat tolerance in the armed forces. BMJ Open. 2020;10(4):1-10.

21. Aden A, Dimba EAO, Ndolo UM, Chindia ML. Socio-economic effects of khat chewing in North Eastern Kenya. East Afr Med J. 2006;83(3):69-73.

22. Gitatui M, Kimani S, Muniu S, Okube O. Determinants of harmful use of alcohol among urban slum dwelling adults in Kenya. Afr Health Sci. 2019;19(4):2906-25.

23. Micheni M, Rogers S, Wahome E, Darwinkel M, Van Der Elst E, Gichuru E, et al. Risk of sexual, physical and verbal assaults on men who have sex with men and female sex workers in coastal Kenya. Aids. 2015;29(0 3):S231-6.

24. Ndetei DM, Khasakhala LI, Mutiso V, Ongecha-Owuor FA, Kokonya DA. Drug use in a rural secondary school in Kenya. Subst Abus. 2010; 31(3):170-3.

25. Ominde BS, Ogeng'o JA, Misiani MK, Kariuki BN. Pattern of stroke in a rural Kenyan hospital. Malawi Med J. 2019;31(1):50-5.

26. Omolo OE, Dhadphale M. Prevalence of khat chewers among primary health clinic attenders in Kenya. Acta Psychiatr Scand. 1987;75(3):318-20.

27. Njuguna J, Olieva S, Muruka C, Owek C. Khat Consumption in Masalani Town, Northeastern Kenya. J Psychoactive Drugs. 2013;45(4):355-9.

28. Thuo J, Ndetei DM, Maru H, Kuria M. The prevalence of personality disorders in a Kenyan inpatient sample. J Pers Disord [Internet]. 2008;22(2):217-20.

29. Dhadphale M. Alcoholism among outpatients with psychiatric morbidity. Indian J Psychiatry. 1997;39(4):300-3.

30. Ndetei DM, Khasakhala L, Maru H, Pizzo M, Mutiso V, Ongecha-Owuor FA, et al. Clinical epidemiology in patients admitted at Mathari Psychiatric Hospital, Nairobi, Kenya. Soc Psychiatry Psychiatr Epidemiol. 2008;43(9):736-42.

31. Kisilu J., Ayuya, S., Ndolo J., Mwavua S. Prevalence And Patterns Of Early Drug Abuse Among Clients Attending Ngara Medically Assisted Therapy Clinic Nairobi, Kenya - A Retrospective Study. AJADA. 2019;1.

32. Maru HM, Kathuku DM, Ndetei DM. Substance use among children and young persons appearing in the Nairobi Juvenile Court, Kenya. East Afr Med J.. 2003; 80: 598-602.

33. Kanyanya IM, Othieno CJ, Ndetei DM. Psychiatric morbidity among convicted male sex offenders at Kamiti Prison, Kenya. East Afr Med J. 2007;84(4):151-5. 
34. Macigo FG, Gathece LW, Guthua SW, Njeru EK, Wagaiyu EG, Mulli TK. Oral hygiene practices and risk of oral leukoplakia. East Afr Med J. 2006;83(4):73-8.

35. Okal J, Geibel S, Muraguri N, Musyoki H, Tun W, Broz D, et al. Estimates of the Size of key populations at risk for HIV infection: Men who have sex with men, female sex workers and injecting drug users in Nairobi, Kenya. Sex Transm Infect. 2013. ;89(5):366-71. Available from: https://pubmed.ncbi.nlm.nih.gov/23761166/

36. Lukandu OM, Koech LS, Kiarie PN. Oral Lesions Induced by Chronic Khat Use Consist Essentially of Thickened Hyperkeratinized Epithelium. Int J Dent. 2015;2015:104812. doi: 10.1155/2015/104812.

37. Lo TQ, Oeltmann JE, Odhiambo FO, Beynon C, Pevzner E, Cain KP, et al. Alcohol use, drunkenness and tobacco smoking in rural western Kenya. Trop Med Int Heal. 2013;18(4):506-15.

38. Kimbui E, Kuria M, Yator O, Kumar M. A cross-sectional study of depression with comorbid substance use dependency in pregnant adolescents from an informal settlement of Nairobi: Drawing implications for treatment and prevention work. Ann Gen Psychiatry [Internet]. 2018;17(1):1-15.

39. Wekesah FM, Nyanjau L, Kibachio J, Mutua MK, Mohamed SF, Grobbee DE, et al. Individual and household level factors associated with presence of multiple non-communicable disease risk factors in Kenyan adults. BMC Public Health. 2018;18(Suppl 3).

40. Bengtson AM, L'Engle K, Mwarogo P, King'Ola N. Levels of alcohol use and history of HIV testing among female sex workers in Mombasa, Kenya. AIDS Care - Psychol Socio-Medical Asp AIDS/HIV. 2014;26(12):1619-24.

41. Chersich MF, Bosire W, King'ola N, Temmerman M, Luchters S. Effects of hazardous and harmful alcohol use on HIV incidence and sexual behaviour: A cohort study of Kenyan female sex workers. Global Health. 2014;10(1):1-11.

42. Pack AP, L’Engle K, Mwarogo P, Kingola N. Intimate partner violence against female sex workers in Mombasa, Kenya. Cult Heal Sex . 2014;16(3):217-30.

43. Wilson KS, Deya R, Masese L, Simoni JM, Stoep A Vander, Shafi J, et al. Prevalence and correlates of intimate partner violence in HIV-positive women engaged in transactional sex in Mombasa, Kenya. Int J STD AIDS. 2016;27(13):1194-203.

44. Muraguri N, Tun W, Okal J, Broz D, Fisher Raymond H, Kellogg T, et al. HIV and STI prevalence and risk factors among male sex workers and other men who have sex with men in nairobi, kenya. J Acquir Immune Defic Syndr. 2015;68(1):91-6.

45. Mokaya AG, Mutiso V, Musau A, Tele A, Kombe Y, Ng'ang'a Z, et al. Substance Use among a Sample of Healthcare Workers in Kenya: A Cross-Sectional Study. J Psychoactive Drugs [Internet]. 2016;48(4):310-9.

46. Ndegwa S, Waiyaki W. Effects of Parental Abandonment and Strife on Youth Drug Use. AJADA. 2020;3.

47. Ngure J, Omulema B, Chepchieng M. Level of risk in substance use among undergraduate students in Kenya: Implications for prevention intervention. AJADA. 2019;1.

48. Kiburi SK, Molebatsi K, Obondo A, Kuria MW. Adverse childhood experiences among patients with substance use disorders at a referral psychiatric hospital in Kenya. BMC Psychiatry. 2018;18(1).

49. Kuria MW, Ndetei DM, Obot IS, Khasakhala LI, Bagaka BM, Mbugua MN, et al. The Association between Alcohol Dependence and Depression before and after Treatment for Alcohol Dependence. ISRN Psychiatry. 2012;1-6.

50. Maina RW, Obondo AA, Kuria MW, Donovan DM. Substance use literacy: Implications for HIV medication adherence and addiction severity among substance users. Afr J Drug Alcohol Stud. 2015;14(2):137-51.

51. Rudatsikira E, Ogwell AE, Siziya S, Muula AS. Prevalence of sexual intercourse among school-going adolescents in Coast Province, Kenya. Tanzan Health Res Bull. 2007;9(3):159-63.

52. Embleton L, Ayuku D, Atwoli L, Vreeman R, Braitstein P. Knowledge, attitudes, and substance use practices among street children in Western Kenya. Subst Use Misuse [Internet]. 2012;47(11):1234-47.

53. Ogwell AEO, Aström AN, Haugejorden O. Socio-demographic factors of pupils who use tobacco in randomly-selected primary schools in Nairobi Province, Kenya. East Afr Med J. 2003;80: 235-41.

54. Khasakhala LI, Ndetei DM, Mathai M, Harder V. Major depressive disorder in a Kenyan youth sample: Relationship with parenting behavior and parental psychiatric disorders. Ann Gen Psychiatry [Internet]. 2013;12(1):1-10.

55. Khasakhala LI, Ndetei DM, Mathai M. Suicidal behaviour among youths associated with psychopathology in both parents and youths attending outpatient psychiatric clinic in Kenya. Ann Gen Psychiatry. 2013;12(1).

56. Winston SE, Chirchir AK, Muthoni LN, Ayuku D, Koech J, Nyandiko W, et al. Prevalence of sexually transmitted infections including HIV in streetconnected adolescents in western Kenya. Sex Transm Infect. 2015;91(5):353-9.

57. Peltzer K. Early smoking initiation and associated factors among in-school male and female adolescents in seven African countries. Afr Health Sci. 2011;11(3):320-8.

58. Kamenderi M, Muteti J, Okioma V, Kimani S. Prevalence and Predictors of Multiple Substance Use Disorders in Kenya. AJADA. $2019 ; 2$.

59. Othieno CJ, Kathuku DM, Ndetei DM. Substance abuse in outpatients attending rural and urban health centres in Kenya. East Afr Med J. 2000;77(11):592-5.

60. Shaffer DN, Njeri R, Justice AC, Odero WW, Tierney WM. Alcohol abuse among patients with and without HIV infection attending public clinics in western Kenya. East Afr Med J. 2004;81(11):594-8.

61. Kinoti KE, Jason LA, Harper GW. Determinants of Alcohol, Khat, and Bhang Use in Rural Kenya. Afr J Drug Alcohol Stud. 2011;10(2):107-18.

62. Jenkins R, Othieno C, Ongeri L, Kiima D, Sifuna P, Kingora J, et al. Alcohol consumption and hazardous drinking in western Kenya-A household survey in a health and demographic surveillance site. BMC Psychiatry. 2015 Sep 25;15(1):1-10.

Page 11/19 
63. Takahashi R, Wilunda C, Magutah K, Mwaura-Tenambergen W, Wilunda B, Perngparn U. Correlates of alcohol consumption in rural western Kenya: A cross-sectional study. BMC Psychiatry. 2017;17(1):175.

64. Ngaruiya C, Abubakar H, Kiptui D, Kendagor A, Ntakuka MW, Nyakundi P, et al. Tobacco use and its determinants in the 2015 Kenya WHO STEPS survey. BMC Public Health. 2018;18(Suppl 3):14-6.

65. Kimani S, Mirie W, Chege M, Okube OT, Muniu S. Association of lifestyle modification and pharmacological adherence on blood pressure control among patients with hypertension at Kenyatta National Hospital, Kenya: A cross-sectional study. BMJ Open. 2019;9(1).

66. Pengpid S, Peltzer K. Alcohol use among adults in Kenya: Results from the National Non-Communicable Diseases Risk Factor survey, 2015. J Psychol Africa [Internet]. 2019 Jan 2 [cited 2021 Jun 5];29(1):49-53.

67. Mungai D, Midigo R. Social and cultural determinants of health; understanding the persisting Alcohol Use Disorder (AUD) in the rural populations in central Kenya. AIMS Public Heal. 2019;6(4):600-14.

68. Christensen DL, Friis H, Mwaniki DL, Kilonzo B, Tetens I, Boit MK, et al. Prevalence of glucose intolerance and associated risk factors in rural and urban populations of different ethnic groups in Kenya. Diabetes Res Clin Pract. 2009;84(3):303-10.

69. Kimando MW, Otieno FCF, Ogola EN, Mutai K. Adequacy of control of cardiovascular risk factors in ambulatory patients with type 2 diabetes attending diabetes out-patients clinic at a county hospital, Kenya. BMC Endocr Disord. 2017;17(1):1-11.

70. Mburu JW, Kingwara L, Ester M, Andrew N. Prognostic factors among TB and TB/DM comorbidity among patients on short course regimen within Nairobi and Kiambu counties in Kenya. J Clin Tuberc Other Mycobact Dis [Internet]. 2018;12(April):9-13.

71. Mohamed SF, Mutua MK, Wamai R, Wekesah F, Haregu T, Juma P, et al. Prevalence, awareness, treatment and control of hypertension and their determinants: Results from a national survey in Kenya. BMC Public Health. 2018;18(Suppl 3).

72. Muture BN, Keraka MN, Kimuu PK, Kabiru EW, Ombeka VO, Oguya F. Factors associated with default from treatment among tuberculosis patients in nairobi province, Kenya: A case control study. BMC Public Health. 2011;11.

73. Winter SC, Obara LM, McMahon S. Intimate partner violence: A key correlate of women's physical and mental health in informal settlements in Nairobi, Kenya. PLoS One. 2020;15(4):1-18.

74. Papas RK, Gakinya BN, Mwaniki MM, Lee H, Kiarie SW, Martino S, et al. Rates and Covariates of Recent Sexual and Physical Violence Against HIVInfected Outpatient Drinkers in Western Kenya. AIDS Behav. 2017;21(8):2243-52.

75. Menach P, Oburra HO, Patel A. Cigarette Smoking and Alcohol Ingestion as Risk Factors for Laryngeal Squamous Cell Carcinoma at Kenyatta National Hospital, Kenya. Clin Med Insights Ear, Nose Throat. 2012;5

76. Patel K, Wakhisi J, Mining S, Mwangi A, Patel R. Esophageal Cancer, the Topmost Cancer at MTRH in the Rift Valley, Kenya, and Its Potential Risk Factors. ISRN Oncol. 2013;2013:1-9.

77. Menya D, Kigen N, Oduor M, Maina SK, Some F, Chumba D, et al. Traditional and commercial alcohols and esophageal cancer risk in Kenya. Int J Cancer [Internet]. 2019 Feb 1 [cited 2021 Jun 8];144(3):459-69.

78. Gathecha GK, Ngaruiya C, Mwai W, Kendagor A, Owondo S, Nyanjau L, et al. Prevalence and predictors of injuries in Kenya: Findings from the national STEPs survey 11 Medical and Health Sciences 1117 Public Health and Health Services. BMC Public Health. 2018;18(S3):1222.

79. Kendagor A, Gathecha G, Ntakuka MW, Nyakundi P, Gathere S, Kiptui D, et al. Prevalence and determinants of heavy episodic drinking among adults in Kenya: Analysis of the STEPwise survey, 2015. BMC Public Health. 2018;18(Suppl 3).

80. Gathecha GK, Ngaruiya C, Mwai W, Kendagor A, Owondo S, Nyanjau L, et al. Prevalence and predictors of injuries in Kenya: Findings from the national STEPs survey 11 Medical and Health Sciences 1117 Public Health and Health Services. BMC Public Health. 2018;18(Suppl 3).

81. Othieno CJ, Okoth R, Peltzer K, Pengpid S, Malla LO. Traumatic experiences, posttraumatic stress symptoms, depression, and health-risk behavior in relation to injury among University of Nairobi students in Kenya. Int J Psychiatry Med. 2015;50(3):299-316.

82. Muthumbi E, Lowe BS, Muyodi C, Getambu E, Gleeson F, Scott JAG. Risk factors for community-acquired pneumonia among adults in Kenya: a casecontrol study. Pneumonia. 2017;9(1):1-9.

83. Kaduka L, Korir A, Oduor CO, Kwasa J, Mbui J, Wabwire S, et al. Stroke distribution patterns and characteristics in Kenya's leading public health tertiary institutions: Kenyatta National hospital and moi teaching and referral hospital. Cardiovasc J Afr. 2018;29(2):68-72.

84. Ayah R, Joshi MD, Wanjiru R, Njau EK, Otieno CF, Njeru EK, et al. A population-based survey of prevalence of diabetes and correlates in an urban slum community in Nairobi, Kenya. BMC Public Health. 2013;13(1).

85. Mundan V, Muiva M, Kimani S. Physiological, Behavioral, and Dietary Characteristics Associated with Hypertension among Kenyan Defence Forces. ISRN Prev Med. 2013;2013:1-8.

86. Joshi MD, Ayah R, Njau EK, Wanjiru R, Kayima JK, Njeru EK, et al. Prevalence of hypertension and associated cardiovascular risk factors in an urban slum in Nairobi, Kenya: A population-based survey. BMC Public Health. 2014;14(1):1-10.

87. Ongeri L, Kirui F, Muniu E, Manduku V, Kirumbi L, Atwoli L, et al. Khat use and psychotic symptoms in a rural Khat growing population in Kenya: A household survey. BMC Psychiatry. 2019;19(1):1-10.

88. Widmann M, Warsame AH, Mikulica J, von Beust J, Isse MM, Ndetei D, et al. Khat use, PTSD and psychotic symptoms among somali refugees in Nairobi - a pilot study. Front Public Heal. 2014;2(JUN):1-10.

89. Mwangi C, Karanja S, Gachohi J, Wanjihia V, Ngang'A Z. Depression, injecting drug use, and risky sexual behavior syndemic among women who inject drugs in Kenya: A cross-sectional survey. Harm Reduct J. 2019;16(1):1-11. 
90. Oyaro M, Wylie J, Chen CY, Ondondo RO, Kramvis A. Human immunodeficiency virus infection predictors and genetic diversity of hepatitis B virus and hepatitis C virus co-infections among drug users in three major Kenyan cities. South Afr J HIV Med. 2018;19(1):1-9.

91. Akiyama MJ, Cleland CM, Lizcano JA, Cherutich P, Kurth AE. Prevalence, estimated incidence, risk behaviours, and genotypic distribution of hepatitis C virus among people who inject drugs accessing harm-reduction services in Kenya: a retrospective cohort study. Lancet Infect Dis. 2019;19(11):1255-63.

92. Papas RK, Gakinya BN, Mwaniki MM, Keter AK, Lee H, Loxley MP, et al. Associations Between the Phosphatidylethanol Alcohol Biomarker and SelfReported Alcohol Use in a Sample of HIV-Infected Outpatient Drinkers in Western Kenya. Alcohol Clin Exp Res [Internet]. 2016;40(8):1779-87.

93. Tsuei SH, Clair V, Mutiso V, Musau A, Tele A, Frank E, Ndetei D. FACTORS INFLUENCING LAY AND PROFESSIONAL HEALTH WORKERS' SELF-EFFICACY IN IDENTIFICATION AND INTERVENTION FOR ALCOHOL, TOBACCO, AND OTHER SUBSTANCE USE DISORDERS IN KENYA. Int J Ment Health Addict. 2017;15(4):766-781.

94. Kurui DK, Ogoncho IM. Determinants of Alcohol Use by Students in Medical Training Colleges in South Nyanza Region, Kenya. AJADA. 2020;3.

95. Ayaya SO, Esamai FO. Health problems of street children in Eldoret, Kenya. East Afr Med J. 2001;78(12):624-9.

96. Kaai SC, Fong GT, Goma F, Meng G, Ikamari L, Ong'ang'o JR, et al. Identifying factors associated with quit intentions among smokers from two nationally representative samples in Africa: Findings from the ITC Kenya and Zambia Surveys. Prev Med Reports. 2019;15:100951.

97. Atwoli L, Mungla PA, Ndung'u MN, Kinoti KC, Ogot EM. Prevalence of substance use among college students in Eldoret, western Kenya. BMC Psychiatry.2011;11(1):34.

98. Åstrøm AN, Ogwell EA. Use of tobacco in Kenya: Sources of information, beliefs and attitudes toward tobacco control measures among primary school students. J Adolesc Heal. 2004;35(3):234-7.

99. Harder VS, Musau AM, Musyimi CW, Ndetei DM, Mutiso VN. A randomized clinical trial of mobile phone motivational interviewing for alcohol use problems in Kenya. Addiction. 2020;115(6):1050-60.

100. L'Engle KL, Mwarogo P, Kingola N, Sinkele W, Weiner DH. A randomized controlled trial of a brief intervention to reduce alcohol use among female sex workers in Mombasa, Kenya. J Acquir Immune Defic Syndr. 2014;67(4):446-53.

101. Papas RK, Sidle JE, Gakinya BN, Baliddawa JB, Martino S, Mwaniki MM, Songole R, Omolo OE, Kamanda AM, Ayuku DO, Ojwang C, Owino-Ong'or WD, Harrington M, Bryant KJ, Carroll KM, Justice AC, Hogan JW, Maisto SA. Treatment outcomes of a stage 1 cognitive-behavioral trial to reduce alcohol use among human immunodeficiency virus-infected out-patients in western Kenya. Addiction. 2011;106(12):2156-66.

102. Parcesepe AM, L'Engle KL, Martin SL, Green S, Suchindran C, Mwarogo P. Early sex work initiation and condom use among alcohol-using female sex workers in Mombasa, Kenya: a cross-sectional analysis. Sex Transm Infect. 2016;92(8):593-598.

103. Widmann M, Apondi B, Musau A, Warsame AH, Isse M, Mutiso V, et al. Comorbid psychopathology and everyday functioning in a brief intervention study to reduce khat use among Somalis living in Kenya: description of baseline multimorbidity, its effects of intervention and its moderation effects on substance use. Soc Psychiatry Psychiatr Epidemiol. 2017;52(11):1425-34.

104. Moscoe E, Agot K, Thirumurthy H. Effect of a Prize-Linked Savings Intervention on Savings and Healthy Behaviors Among Men in Kenya: A Randomized Clinical Trial. JAMA Netw open. 2019;2(9)

105. Muriungi SK, Ndetei DM. Effectiveness of psycho-education on depression, hopelessness, suicidality, anxiety and substance use among basic diploma students at Kenya Medical Training College. South African J Psychiatry. 2013;19(2):41-50.

106. Papas RK, Sidle JE, Martino S, Baliddawa JB, Songole R, Omolo OE, et al. Systematic cultural adaptation of cognitive-behavioral therapy to reduce alcohol use among HIV-infected outpatients in Western Kenya. AIDS Behav. 2010;

107. MacKenzie C, Kiragu K, Odingo G, Yassin R, Shikuku P, Angala P, et al. The feasibility of integrating alcohol risk-reduction counseling into existing VCT services in Kenya. Afr J Drug Alcohol Stud. 2009;8(2):73-80.

108. Perl R, Murukutla N, Occleston J, Bayly M, Lien M, Wakefield M, et al. Responses to antismoking radio and television advertisements among adult smokers and non-smokers across Africa: Message-testing results from Senegal, Nigeria and Kenya. Tob Control. 2015;24(6):601-8.

109. Giusto A, Green EP, Simmons RA, Ayuku D, Patel P, Puffer ES. A multiple baseline study of a brief alcohol reduction and family engagement intervention for fathers in Kenya. J Consult Clin Psychol. 2020;88(8):708-25.

110. Takahashi R, Wilunda C, Magutah K, Mwaura-Tenambergen W, Atwoli L, Perngparn U. Evaluation of alcohol screening and community-based brief interventions in rural western Kenya: A quasi-experimental study. Alcohol Alcohol. 2018;53(1):121-8.

111. Deveau CS, Tengia L, Mutua C, Njoroge S, Dajoh L, Singer B. Utilisation of community-based addiction out-patient treatment programmes in Kenya. Afr J Drug Alcohol Stud. 2010;9(2)

112. Gichuki JW, Opiyo R, Mugyenyi P, Namusisi K. Healthcare providers' level of involvement in provision of smoking cessation interventions in public health facilities in Kenya. J Public Health Africa. 2016;6(2):62-7.

113. Rhodes T. The becoming of methadone in Kenya: How an intervention's implementation constitutes recovery potential. Soc Sci Med. 2018 Mar;201:7179. doi: 10.1016/j.socscimed.2018.02.007.

114. Muturi N. Community Perspectives on Communication Strategies for Alcohol Abuse Prevention in Rural Central Kenya. J Health Commun. 2016;21(3):309-17.

115. Ndimbii JN, Guise A, Ayon S, Kalama M, McLean S, Rhodes T. Implementing needle and syringe programmes in Kenya: Changes, opportunities and challenges in HIV prevention. Afr J Drug Alcohol Stud. 2015;14(2):95-103.

116. Rhodes T, Guise A, Ndimbii J, Strathdee S, Ngugi E, Platt L, et al. Is the promise of methadone Kenya's solution to managing HIV and addiction? A mixedmethod mathematical modelling and qualitative study. BMJ Open. 2015;5(3).

Page $13 / 19$ 
117. Guise A, Dimova M, Ndimbii J, Clark P, Rhodes T. A qualitative analysis of transitions to heroin injection in Kenya: Implications for HIV prevention and harm reduction. Harm Reduct J [Internet]. 2015;12(1):1-9.

118. Syvertsen JL, Agot K, Ohaga S, Bazzi AR. You can't do this job when you are sober: Heroin use among female sex workers and the need for comprehensive drug treatment programming in Kenya. Drug Alcohol Depend. 2019;194:495-499. doi:10.1016/j.drugalcdep.2018.10.019

119. Yotebieng KA, Agot K, Rota G, Cohen CR, Syvertsen JL. A qualitative study of substance use during pregnancy: Implications for reproductive healthcare in Western Kenya. Afr J Reprod Health [Internet]. 2016 Dec 1 [cited 2021 Jun 8];20(4):51-9.

120. Njue C, Voeten HACM, Remes P. Disco funerals: A risk situation for HIV infection among youth in Kisumu, Kenya. Aids. 2009;23(4):505-9.

121. Velloza J, L'Engle K, Mwarogo P, Chokwe J, Magaria L, Sinkele W, et al. Stages and Processes of Change Utilized by Female Sex Workers Participating in an Alcohol-Reduction Intervention in Mombasa, Kenya. Subst Use Misuse. 2015;50(13):1728-37.

122. Kibicho J, Campbell JK. Community perspectives of second-generation alcohol misuse and HIV risk in rural Kenya: A gendered syndemic lens. Glob Public Health. 2019;14(12):1733-43.

123. Muturi N. Gender and HIV infection in the context of alcoholism in Kenya. African J AIDS Res. 2015;14(1):57-65.

124. Mburu G, Ayon S, Tsai AC, Ndimbii J, Wang B, Strathdee S, et al. "Who has ever loved a drug addict? It's a lie. They think a 'teja' is as bad person": Multiple stigmas faced by women who inject drugs in coastal Kenya. Harm Reduct J. 2018;15(1):1-8.

125. Mburu G, Ayon S, Mahinda S, Kaveh K. Determinants of Women's Drug Use During Pregnancy: Perspectives from a Qualitative Study. Matern Child Health J [Internet]. 2020;24(9):1170-8.

126. Mburu G, Limmer M, Holland P. HIV risk behaviours among women who inject drugs in coastal Kenya: Findings from secondary analysis of qualitative data. Harm Reduct J [Internet]. 2019 Feb 6 [cited 2021 Jun 9];16(1):10.

127. Mburu G, Limmer M, Holland P. Role of boyfriends and intimate sexual partners in the initiation and maintenance of injecting drug use among women in coastal Kenya. Addict Behav [Internet]. 2019;93:20-8.

128. Mburu G, Ndimbii J, Ayon S, Mlewa O, Mbizvo M, Kihara C, et al. Contraceptive Use Among Women Who Inject Drugs: Motivators, Barriers, and Unmet Needs. Women's Reprod Heal [Internet]. 2018; 5(2):99-116.

129. Mital S, Miles G, McLellan-Lemal E, Muthui M, Needle R. Heroin shortage in Coastal Kenya: A rapid assessment and qualitative analysis of heroin users' experiences. Int J Drug Policy. 2016;30:91-98. doi:10.1016/j.drugpo.2015.08.010

130. Muturi N. Alcohol consumption and reproductive health risks in rural Central Kenya. Sex Reprod Healthc. 2014;5(2):41-6.

131. Ssewanyana D, Mwangala PN, Marsh V, Jao I, van Baar A, Newton CR, et al. Socio-ecological determinants of alcohol, tobacco, and drug use behavior of adolescents in Kilifi County at the Kenyan coast. J Health Psychol [Internet]. 2018;25(12).

132. Ezard N, Oppenheimer E, Burton A, Schilperoord M, MacDonald D, Adelekan M, et al. Six rapid assessments of alcohol and other substance use in populations displaced by conflict. Confl Health. 2011;5(1):1-15.

133. Beckerleg S. How "Cool” is Heroin Injection at the Kenya Coast. Drugs Educ Prev Policy. 2004;11(1):67-77.

134. Njue, C., Voeten, H.A. \& Remes, P. Porn video shows, local brew, and transactional sex: HIV risk among youth in Kisumu, Kenya. BMC Public Health 11, 635 (2011). https://doi.org/10.1186/1471-2458-11-635

135. Othieno CJ, Obondo A, Mathai M. Improving adherence to ante-retroviral treatment for people with harmful alcohol use in Kariobangi, Kenya through participatory research and action. BMC Public Health.2012;12(1):1.

136. Syvertsen JL, Ohaga S, Agot K, Dimova M, Guise A, Rhodes T, Wagner KD. An ethnographic exploration of drug markets in Kisumu, Kenya. Int J Drug Policy. 2016 Apr;30:82-90. doi: 10.1016/j.drugpo.2016.01.001.

137. Ndimbii J, Ayon S, Abdulrahman T, Mahinda S, Jeneby F, Armstrong G, et al. Access and utilisation of reproductive, maternal, neonatal and child health services among women who inject drugs in coastal Kenya: Findings from a qualitative study. Sex Reprod Healthc. 2018 Dec 1;18:48-55.

138. Mburu G, Limmer M, Holland P. HIV risk behaviours among women who inject drugs in coastal Kenya: Findings from secondary analysis of qualitative data. Harm Reduct J [Internet]. 2019; 16(1):10.

139. Mokaya AG, Mutiso V, Musau A, Tele A, Kombe Y, Ng'ang'a Z, et al. Substance Use among a Sample of Healthcare Workers in Kenya: A Cross-Sectional Study. J Psychoactive Drugs [Internet]. 2016; 48(4):310-9.

140. Kurui DK, Ogoncho IM. Prevalence of Substance Abuse among Students in Medical Training Colleges in South Nyanza Region, Kenya. AJADA. $2019 ; 2$.

141. United Nations Office on Drugs and Crime. New psychoactive substances.2020. https://www.unodc.org/documents/scientific/NPSLeaflet_WEB_2020.pdf. Accessed 12 June 2021

142. Yapa, H.M., Bärnighausen, T. Implementation science in resource-poor countries and communities. Implementation Sci 13, 154 (2018). https://doi.org/10.1186/s13012-018-0847-1

143. World Health Organisation 2017. 'Best Buys' and Other Recommended Interventions for the Prevention and Control of Noncommunicable Diseases; "the updated Appendix 3 of the WHO Global NCD Action Plan 2013-2020. https://www.who.int/ncds/management/WHO_Appendix_BestBuys.pdf. Accessed 12 June 2021

144. Green EP, Lai Y, Pearson N, Rajasekharan S, Rauws M, Joerin A, et al. Expanding access to perinatal depression treatment in Kenya through automated psychological support: Development and usability study. JMIR Form Res. 2020;4(10).

145. Business Today. Kenya leads Africa in smartphone usage [Internet]. 2020. Available from: https://businesstoday.co.ke/kenya-leads-africa-smartphoneusage/. Accessed 12 June 2021.

146. Wang D, Wang Y, Wang Y, Li R, Zhou C. Impact of physical exercise on substance use disorders: A meta-analysis. PLoS One. 2014; 9(10):110728. 
147. Li W, Howard MO, Garland EL, McGovern P, Lazar M. Mindfulness treatment for substance misuse: A systematic review and meta-analysis. J Subst Abuse Treat. 2017;75:62-96.

148. Nielsen MFJ, Resnick CA, Acuda SW. Alcoholism Among Outpatients of a Rural District General Hospital in Kenya. Br J Addict. 1989;84(11):1343-51.

149. Kaplan M, Carriker L, Waldron I. Gender differences in tobacco use in Kenya. Soc Sci Med. 1990;30(3):305-10.

150. Hall W, Saunders JB, Babor TF, Aasland OG, Amundsen A, Hodgson R, et al. The structure and correlates of alcohol dependence: WHO collaborative project on the early detection of persons with harmful alcohol consumption-III. Addiction. 1993;88(12):1627-36.

151. Saunders JB, Aasland OG, Amundsen A, Grant M. Alcohol consumption and related problems among primary health care patients: WHO Collaborative Project on Early Detection of Persons with Harmful Alcohol Consumption-I. Addiction. 1993;88(3):349-62.

152. Kwamanga DHO, Odhiambo JA, Gicheha C. Tobacco consumption among primary school teachers in nairobi. East Afr Med J. 2001;78(3):119-23.

153. Kwamanga DHO, Odhiambo JA, Amukoye El. Prevalence and risk factors of smoking among secondary school students in Nairobi. East Afr Med J. 2003;80(4):207-12.

154. Kamotho C, Ogola EO, Joshi M, Gikonyo D. Cardiovascular risk factor profile of Black Africans undergoing coronary angiography. East Afr Med J. 2004;81(2):82-6.

155. Beckerleg S, Telfer M, Sadiq A. A rapid assessment of heroin use in Mombasa, Kenya. Subst Use Misuse. 2006;41(6-7):1029-44.

156. Cleland CM, Des Jarlais DC, Perlis TE, Stimson G, Poznyak V, Adelekan M, et al. HIV risk behaviors among female IDUs in developing and transitional countries. BMC Public Health [Internet]. 2007 Dec 1 [cited 2021 Jun 6];7(1):271.

157. Sanders EJ, Graham SM, Okuku HS, Van Der Elst EM, Muhaari A, Davies A, et al. HIV-1 infection in high risk men who have sex with men in Mombasa, Kenya. Aids. 2007;21(18):2513-20.

158. Ndetei D, Khasakhala L, Ong'echa F, Kokonya D, Mutiso V, Kuria M, et al. A study of drug use in five urban centres in Kenya. Afr J Drug Alcohol Stud. 2009;7(1).

159. Komu P, Dimba EAO, Macigo FG, Ogwell AEO. Cigarette smoking and oral health among healthcare students. East Afr Med J. 2009;86(4):178-82.

160. Ndetei DM, Khasakhala LI, Mutiso V, Ongecha-Owuor FA, Kokonya DA. Patterns of drug abuse in public secondary schools in Kenya. Subst Abus. 2009;30(1):69-78.

161. Ndetei DM, Khasakhala LI, Mutiso V, Ongecha-Owuor FA, Kokonya DA. Psychosocial and health aspects of drug use by students in public secondary schools in Nairobi, Kenya. Subst Abus. 2009;30(1):61-8.

162. Nguchu HK, Joshi MD, Otieno CF. Acute coronary syndromes amongst type 2 diabetics with ischaemic electrocardiograms presenting to Accident and Emergency department of a Kenyan Tertiary Institution. East Afr Med J. 2009;86(10):463-8.

163. Peltzer K. Prevalence and correlates of substance use among school children in six African countries. Int J Psychol [Internet]. 2009; 44(5):378-86.

164. Tegang SP, Abdallah S, Emukule G, Luchters S, Kingola N, Barasa M, et al. Concurrent sexual and substance-use risk behaviors. 2010;7(4):10-6.

165. Luchters S, Geibel S, Syengo M, Lango D, King'Ola N, Temmerman M, et al. Use of AUDIT, and measures of drinking frequency and patterns to detect associations between alcohol and sexual behaviour in male sex workers in Kenya. BMC Public Health. 2011;11:1-8.

166. Ndugwa RP, Kabiru CW, Cleland J, Beguy D, Egondi T, Zulu EM, et al. Adolescent problem behavior in nairobi's informal settlements: Applying problem behavior theory in Sub-Saharan Africa. J Urban Heal. 2011;88(SUPPL. 2):298-317.

167. Ndetei DM, Khasakhala L, Meneghini L, Aillon JL. The_relationship_between_schizo-affective and mood disorders in patients. 2013;(March):110-7.

168. Embleton L, Atwoli L, Ayuku D, Braitstein P. The Journey of Addiction: Barriers to and Facilitators of Drug Use Cessation among Street Children and Youths in Western Kenya. PLoS One. 2013;8(1).

169. Kinyanjui DWC, Atwoli L. Substance use among inmates at the Eldoret prison in Western Kenya. BMC Psychiatry. $2013 ; 13$.

170. Njoroge A, Guthrie BL, Bosire R, Wener M, Kiarie J, Farquhar C. Low HDL-cholesterol among HIV-1 infected and HIV-1 uninfected individuals in Nairobi, Kenya. Lipids Health Dis [Internet]. 2017;16(1):110.

171. Ploubidis GB, Mathenge W, De Stavola B, Grundy E, Foster A, Kuper H. Socioeconomic position and later life prevalence of hypertension, diabetes and visual impairment in Nakuru, Kenya. Int J Public Health. 2013;58(1):133-41.

172. Balogun O, Koyanagi A, Stickley A, Gilmour S, Shibuya K. Alcohol consumption and psychological distress in adolescents: A multi-country study. J Adolesc Heal. 2014;54(2):228-34.

173. De Menil VP, Knapp M, McDaid D, Njenga FG. Service use, charge, and access to mental healthcare in a private kenyan inpatient setting: The effects of insurance. PLoS One. 2014;9(3):1-7.

174. Medley A, Seth P, Pathak S, Howard AA, Deluca N, Matiko E, et al. Alcohol use and its association with HIV risk behaviors among a cohort of patients attending HIV clinical care in Tanzania, Kenya, and Namibia. AIDS Care - Psychol Socio-Medical Asp AIDS/HIV. 2014;26(10):1288-97.

175. Othieno CJ, Okoth RO, Peltzer K, Pengpid S, Malla LO. Depression among university students in Kenya: Prevalence and sociodemographic correlates. J Affect Disord. 2014;165:120-5.

176. Were T, Wesongah JO, Munde E, Ouma C, Kahiga TM, Ongecha-Owuor F, et al. Clinical chemistry profiles in injection heroin users from Coastal Region, Kenya. BMC Clin Pathol. 2014;14(1):1-9.

177. Goldblatt A, Kwena Z, Lahiff M, Agot K, Minnis A, Prata N, et al. Prevalence and correlates of HIV infection among street boys in Kisumu, Kenya. PLoS One. 2015;10(10):1-22. 
178. Hulzebosch A, van de Vijver S, Oti SO, Egondi T, Kyobutungi C. Profile of people with hypertension in Nairobi's slums: A descriptive study. Global Health [Internet]. 2015;11(1):1-7.

179. Kurth AE, Cleland CM, Des Jarlais DC, Musyoki H, Lizcano JA, Chhun N, et al. HIV prevalence, estimated incidence, and risk behaviors among people who inject drugs in Kenya. J Acquir Immune Defic Syndr. 2015;70(4):420-7.

180. Olack B, Wabwire-Mangen F, Smeeth L, Montgomery JM, Kiwanuka N, Breiman RF. Risk factors of hypertension among adults aged 35-64 years living in an urban slum Nairobi, Kenya. BMC Public Health. 2015;15(1):1-9.

181. Onsomu EO, Abuya BA, Okech IN, Rosen DL, Duren-Winfield V, Simmons AC. Association Between Domestic Violence and HIV Serostatus Among Married and Formerly Married Women in Kenya. Health Care Women Int. 2015;36(2):205-28.

182. Othieno CJ, Okoth R, Peltzer K, Pengpid S, Malla LO. Risky HIV sexual behaviour and depression among University of Nairobi students. Ann Gen Psychiatry. 2015;14(1):1-8.

183. Secor AM, Wahome E, Micheni M, Rao D, Simoni JM, Sanders EJ, et al. Depression, substance abuse and stigma among men who have sex with men in coastal Kenya. Aids. 2015;29(0 3):S251-9.

184. Syvertsen JL, Agot K, Ohaga S, Strathdee SA, Camlin CS, Omanga E, et al. Evidence of injection drug use in Kisumu, Kenya: IMPLICATIONS for HIV prevention. Drug Alcohol Depend [Internet]. 2015;151:262-6.

185. Tun W, Sheehy M, Broz D, Okal J, Muraguri N, Raymond HF, et al. HIV and STI Prevalence and Injection Behaviors Among People Who Inject Drugs in Nairobi: Results from a 2011 Bio-behavioral Study Using Respondent-Driven Sampling. AIDS Behav. 2015;19(1):24-35.

186. Mokaya AG, Mutiso V, Musau A, Tele A, Kombe Y, Ng'ang'a Z, et al. Substance Use among a Sample of Healthcare Workers in Kenya: A Cross-Sectional Study. J Psychoactive Drugs. 2016;48(4):310-9.

187. White D, Wilson KS, Masese LN, Wanje G, Jaoko W, Mandaliya K, et al. Alcohol use and associations with biological markers and self-reported indicators of unprotected sex in human immunodeficiency virus-positive female sex workers in Mombasa, Kenya. Sex Transm Dis [Internet]. 2016; $43(10): 642-7$.

188. Embleton L, Nyandat J, Ayuku D, Sang E, Kamanda A, Ayaya S, et al. Sexual Behavior Among Orphaned Adolescents in Western Kenya: A Comparison of Institutional- and Family-Based Care Settings. J Adolesc Heal [Internet]. 2017;60(4):417-24.

189. Goodman ML, Grouls A, Chen CX, Keiser PH, Gitari S. Adverse Childhood Experiences Predict Alcohol Consumption Patterns Among Kenyan Mothers. Subst Use Misuse [Internet]. 2017;52(5):632-8.

190. Kamau JW, Omigbodun OO, Bella-Awusah T, Adedokun B. Who seeks child and adolescent mental health care in Kenya? A descriptive clinic profile at a tertiary referral facility. Child Adolesc Psychiatry Ment Health. 2017;11(1):14.

191. Kunzweiler CP, Bailey RC, Okall DO, Graham SM, Mehta SD, Otieno FO. Factors Associated with Prevalent HIV Infection among Kenyan MSM: The Anza Mapema Study. J Acquir Immune Defic Syndr. 2017;76(3):241-9.

192. Kwobah E, Epstein S, Mwangi A, Litzelman D, Atwoli L. PREVALENCE of psychiatric morbidity in a community sample in Western Kenya. BMC Psychiatry. 2017;17(1).

193. Roth EA, Benoit C, Jansson M, Hallsgrimdottir H. Public Drinking Venues as Risk Environments: Commercial Sex, Alcohol and Violence in a Large Informal Settlement in Nairobi, Kenya. Hum Ecol [Internet]. 2017;45(2):277-83.

194. Takahashi R, Wilunda C, Magutah K, Mwaura-Tenambergen W, Wilunda B, Perngparn U. Correlates of alcohol consumption in rural western Kenya: A cross-sectional study. BMC Psychiatry. 2017;17(1):1-10.

195. Asiki G, Mohamed SF, Wambui D, Wainana C, Muthuri S, Ramsay M, et al. Sociodemographic and behavioural factors associated with body mass index among men and women in Nairobi slums: AWI-Gen Project. Glob Health Action.2018;11(sup2).

196. Budambula V, Matoka C, Ouma J, Ahmed AA, Otieno MF, Were T. Socio-demographic and sexual practices associated with HIV infection in Kenyan injection and non-injection drug users. BMC Public Health.2018; 18(1):193.

197. Cagle A, Mcgrath C, Richardson BA, Donovan D, Yatich N, Ngomoa R, et al. Alcohol use and immune reconstitution among HIV-infected patients on antiretroviral therapy in Nairobi, Kenya Anthony. AIDS Care. 2018;29(9):1192-7.

198. Korhonen C, Kimani M, Wahome E, Otieno F, Okall D, Bailey RC, et al. Depressive symptoms and problematic alcohol and other substance use in 1476 gay, bisexual, and other MSM at three research sites in Kenya. Aids. 2018;32(11):1507-15.

199. Kunzweiler CP, Bailey RC, Okall DO, Graham SM, Mehta SD, Otieno FO. Depressive Symptoms, Alcohol and Drug Use, and Physical and Sexual Abuse Among Men Who Have Sex with Men in Kisumu, Kenya: The Anza Mapema Study. AIDS Behav. 2018;22(5):1517-29.

200. Magati P, Drope J, Mureithi L, Lencucha R. Socio-economic and demographic determinants of tobacco use in Kenya: Findings from the Kenya demographic and health survey 2014. Pan Afr Med J. 2018;30:1-10.

201. Mannik JR, Figol A, Churchill V, Aw J, Francis S, Karino E, et al. Innovation in cardiovascular risk using a novel mHealth tool in rural Kenya. J Innov Heal Inf. 2018;25(3):176-82.

202. Mkuu RS, Barry AE, Montiel Ishino FA, Amuta AO. Examining characteristics of recorded and unrecorded alcohol consumers in Kenya. BMC Public Health. 2018;18(1):1-8.

203. Ng'ang'a A, Nyangasi M, Nkonge NG, Gathitu E, Kibachio J, Gichangi P, et al. Predictors of cervical cancer screening among Kenyan women: Results of a nested case-control study in a nationally representative survey. BMC Public Health. 2018;18(Suppl 3).

204. Tang S, Bishwajit G, Luba TR, Yaya S. Prevalence of smoking among men in Ethiopia and Kenya: A cross-sectional study. Int J Environ Res Public Health. 2018;15(6). 
205. Anundo J. Prevalence of Depression among Female Injecting Drug Users (FIDUs): Study of a Drop-in Rehabilitation Center in Nairobi County, Kenya. AJADA. 2019;1.

206. Haregu TN, Oti S, Egondi T, Kyobutungi C. Co-occurrence of behavioral risk factors of common non-communicable diseases among urban slum dwellers in Nairobi, Kenya. Glob Health Action. 2015;8(1).

207. Kamenderi M, Muteti J, Okioma V, Nyamongo I, Kimani S, Kanana F, Kahiu C. Status of Drugs and Substance Use among Secondary School Students in Kenya. AJADA. 2019; 1

208. Kamenderi M, Muteti J, Okioma V, Kimani S, Kanana F, Kahiu C. Status of Drugs and Substance Abuse among the General Population in Kenya. AJADA. 2019;1.

209. Mutiso VN, Musyimi CW, Krolinski P, Neher CM, Musau AM, Tele A, et al. Relationship between Bullying, Substance Use, Psychiatric Disorders, and Social Problems in a Sample of Kenyan Secondary Schools. Prev Sci. 2019;20(4):544-54.

210. Nall A, Chenneville T, Rodriguez LM, O’Brien JL. Factors affecting hiv testing among youth in kenya. Int J Environ Res Public Health. 2019;16(8):1-14.

211. Owuor. Relationship Between Attachment Styles And Risk For Problematic Drug Use Among Undergraduate Students In Selected Universities In Kenya. AJADA. 2019;2.

212. Woldu DO, Haile ZT, Howard S, Walther C, Otieno A, Lado B. Association between substance use and concurrent sexual relationships among urban slum dwellers in Nairobi, Kenya. AIDS Care - Psychol Socio-Medical Asp AIDS/HIV. 2019;31(11):1454-60.

213. Mutai C, Ombachi N, Simiyu R. Innovations and Opportunities In Social Media For Management Of Drug And Substance Abuse In Selected Informal Settlements of Nairobi County, Kenya. AJADA. 2020;3.

214. Bazzi AR, Yotebieng K, Otticha S, Rota G, Agot K, Ohaga S, et al. PrEP and the syndemic of substance use, violence, and HIV among female and male sex workers: a qualitative study in Kisumu, Kenya. J Int AIDS Soc. 2019;22(4).

215. Guise A, Ndimbii J, Igonya EK, Owiti F, Strathdee SA, Rhodes T. Integrated and differentiated methadone and HIV care for people who use drugs: A qualitative study in Kenya with implications for implementation science. Health Policy Plan. 2019. 2021;34(2):110-9.

216. Kamenderi M, Muteti J, Okioma V, Kimani S, Effects of Environment and Parenting Practices on Alcohol Use among Primary School Pupils in Kenya. AJADA. 2020;3.

\section{Figures}




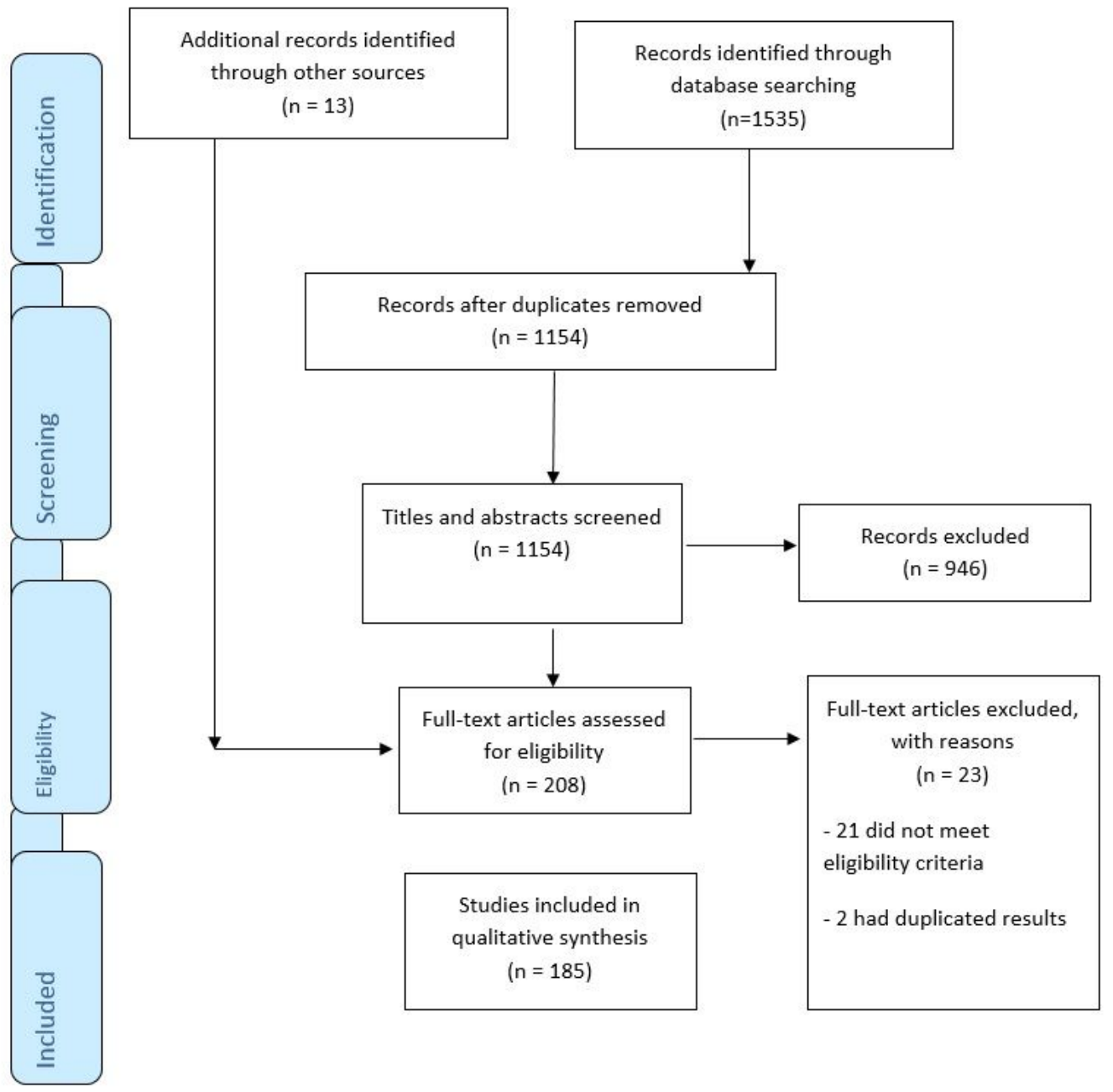

Figure 1

PRISMA flow chart diagram describing selection of studies for the systematic review mapping existing literature on substance use and SUD in Kenya.

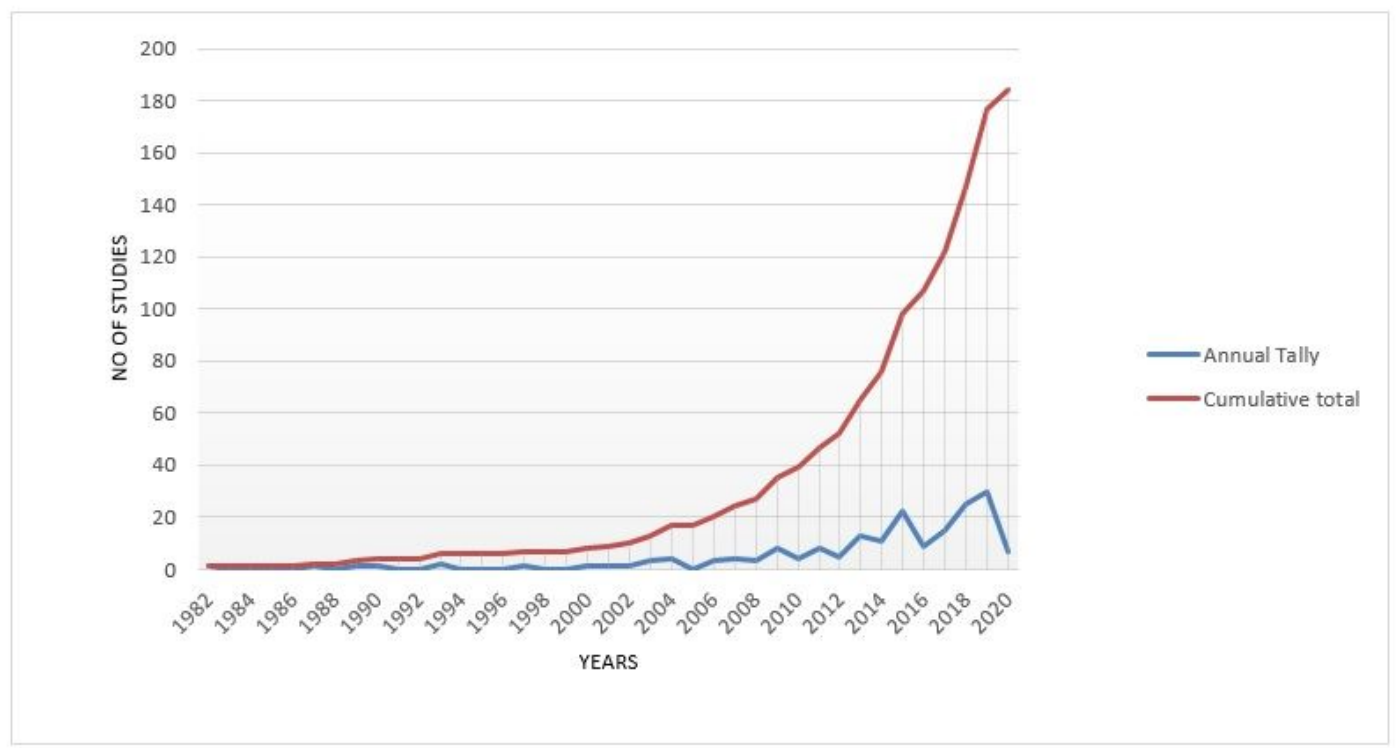

\section{Figure 2}

Line graph showing the trends in publications on substance use/SUD in Kenya since inception 


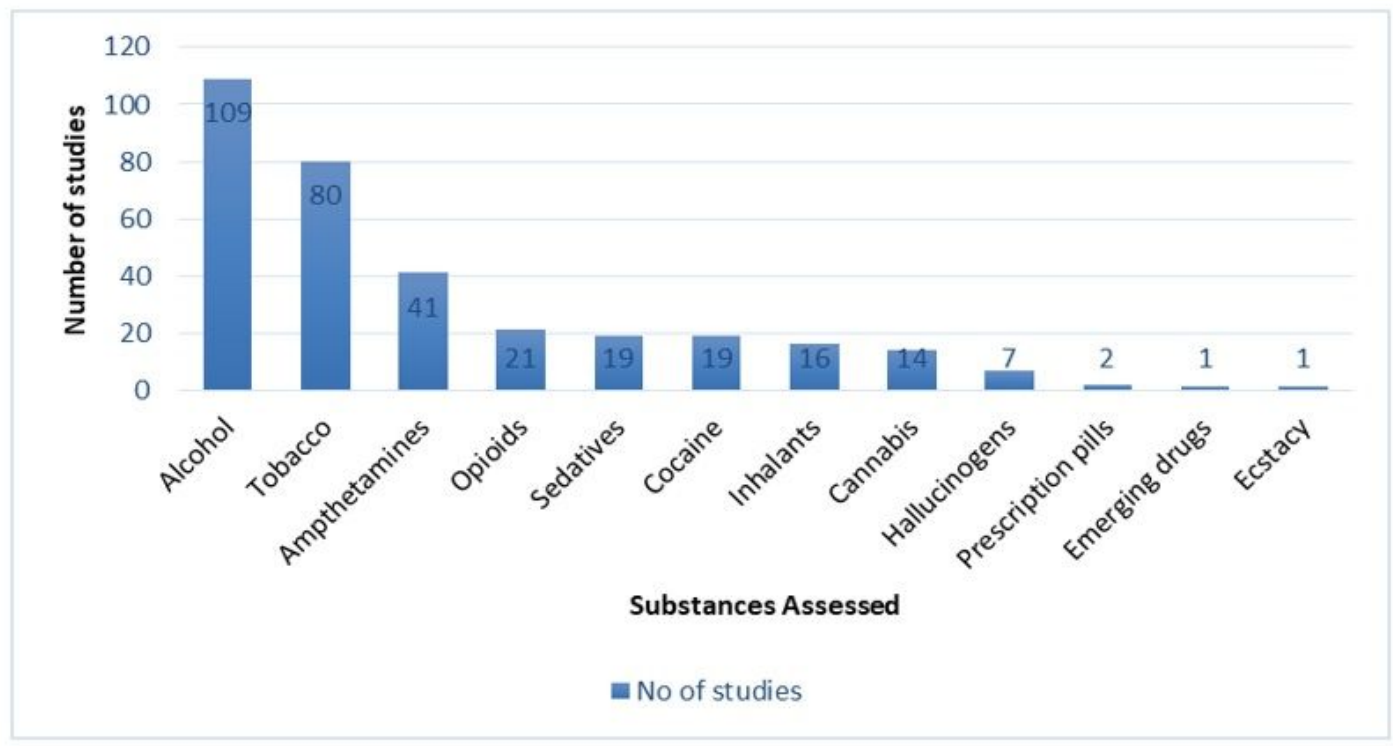

Figure 3

Bar chart showing the number of studies evaluating prevalence/risk factors for each substance

\section{Supplementary Files}

This is a list of supplementary files associated with this preprint. Click to download.

- Additionalfile1PRISMAChecklist.docx

- Additionalfile2Psychinfosearchterms.pdf

- Additionalfile3Epidemiologicalstudies.docx

- Additionalfile4Studiesevaluatinginterventions.docx

- Additionalfile5Qualitativestudies.docx

- Additionalfile6QualityAssessment.docx 